\title{
Optic nerve injury in preoperative imaging is associated with visual improvement outcome in endoscopic optic nerve decompression
}

\author{
Isabella Leitner - Alexandros Andrianakis (D) - Verena Gellner · Peter Kiss - Damianos Andrianakis • \\ Peter Valentin Tomazic
}

Received: 11 January 2021 / Accepted: 28 June 2021 / Published online: 3 August 2021

(C) The Author(s) 2021

\begin{abstract}
Summary
Objective To evaluate potential clinical parameters having an impact on visual outcome after endoscopic optic nerve decompression in acute optic neuropathy patients.

Methods A retrospective chart review of patients with acute optic neuropathy, who underwent endoscopic optic nerve decompression between June 2001 and November 2018 at an academic center was performed. Patients were divided into groups according to visual improvement after surgical treatment (yes/no). Following clinical parameters were compared between groups: perioperative steroid use, evidence of optic nerve affection in preoperative neuroimaging, additional optic nerve sheath incision, surgery delay and preoperative C-reactive protein (CRP) levels. Further subgroups analyses were conducted based on etiology (trauma/tumor).

Results Among 32 included cases, 16 patients (50\%) reported visual improvement after endoscopic op-
\end{abstract}

The authors I. Leitner and A. Andrianakis contributed equally as first authors to this work.

Availability of data and material The datasets generated and analyzed during the current study are available from the corresponding author on reasonable request.

I. Leitner · A. Andrianakis $(\bowtie) \cdot$ P. Kiss · P. V. Tomazic

Department of Otorhinolaryngology, Head

and Neck Surgery, Medical University of Graz,

Auenbruggerplatz 26, $8036 \mathrm{Graz}$, Austria

alexandros.andrianakis@medunigraz.at

V. Gellner

Department for Neurosurgery, Medical University of Graz,

Graz, Austria

D. Andrianakis

Institute of Mathematics and Scientific Computing,

University of Graz, Graz, Austria tic nerve decompression. There was no significant difference in visual improvement between etiology subgroups (trauma: $n=9 / 20(45 \%)$ vs. tumor: $n=7 / 12$ (58.3\%), $p=0.465)$. Tumor subgroup patients with visual improvement had a significantly higher prevalence of optic nerve affection in preoperative neuroimaging than those without visual improvement $(p=0.018, \varphi=0.683)$. Perioperative steroid administration was negatively associated with visual outcome $(p=0.034, \varphi=0.375)$. Nerve sheath incision, surgery delay and preoperative CRP levels did not have a significant impact on visual outcome ( $p>0.05)$.

Conclusion Radiological findings can help as an indicator for surgical treatment since an affected optic nerve in preoperative neuroimaging resulted in better visual outcome after surgery. The use of steroids should be considered more carefully since it did not show any beneficial effect.

Keywords Acute optic neuropathy - Optic nerve sheath incision · Steroid treatment · Endoscopic sinus surgery

\section{Introduction}

Acute optic neuropathy can be defined as acute damage to the optic nerve resulting in prompt ophthalmologic symptoms like blurry vision, decreased color vision, scotomas, visual field defects and visual impairment. Causes include optic nerve ischemia, inflammation, tumor compression and traumatic optic nerve injury [1].

The diagnosis is based on medical history, physical examination and neuroimaging. Survey of patient's anamnesis should involve besides the general medical history (e.g. pre-existing comorbidities, medication intake, family medical history) and complaints/ symptoms, the presence of a recent trauma in order 
to quickly differentiate between a traumatic or nontraumatic etiology. The physical examination is focused on the ophthalmological assessment, including the measurement of the visual acuity, pupillary light reaction, fundoscopy and perimetry. Neuroimaging is obligatory for evaluation of optic nerve lesions and signs of fracture. Computed tomography (CT) is often the preferred primary imaging modality, especially in traumatic cases [1-5]. The examination is fast, costeffective, not limited by the use of potential foreign bodies and it excellently detects bony fractures and bony fragments comprising the optic nerve. Moreover, CT imaging can identify lesions nearby the optic nerve and inside the orbit, causing damage to the nerve by direct compression or infiltration [6-8]. Nevertheless, magnetic resonance imaging (MRI) is the gold standard in the diagnosis of soft tissue. Therefore, particularly in nontraumatic cases the MRI is the imaging modality of choice for a precise evaluation of the orbit, optic nerve and surrounding area [9-11].

The therapeutic management primarily targets the improvement and maintenance of visual function. In this context, the optimal therapeutic approach in literature appears inconstant. Currently available treatment options are corticosteroids and surgical optic nerve decompression [12, 13].

The therapeutic use of corticosteroids for acute optic neuropathies is mainly based upon their ability to relieve inflammations and edema, being neuroprotective and antioxidative [14-16]. Possible positive effects of steroids are suppression of immunological mediators, shorter hospitalization and a better recovery time [17]. An experimental study of Lew et al. [18] showed that a high-dose steroid therapy can increase the blood flow of the optic nerve in rabbits. Visual improvement was seen in patients who were treated within a short time frame after injury [14-16]. Reported harmful effects, especially due to high doses, are increased mortality, a worse survival rate and increased axonal loss [16, 19, 20]. A clear benefit of steroids and when they should be given has not been stated clearly thus far $[6,21]$. Moreover, they may be given in combination with surgery or as a single medical treatment [14-16].

Along with the introduction of functional endoscopic sinus surgery and the subsequently developed endoscopic skull base surgery, surgical decompression of the optic nerve as treatment option for traumatic optic nerve injuries and compressive optic neuropathies gained popularity in the past decades. Indications for surgical optic nerve decompression include a traumatic nerve injury and compressive neuropathies, e.g. adenomas of the pituitary gland (incidence 74-94/100,000 cases per year), fibrous dysplasia (incidence 15/100,000 cases per year) endocrine orbitopathy (incidence 2.9-16/100,000 cases per year), aneurysm close by the optic nerve (incidence $1.4 / 100,000$ cases per year), craniopharyngiomas (incidence $0.2-5 / 100,000$ cases per year) and optic nerve sheath meningiomas (2\% of orbital tumors, very rare and associated with neurofibromatosis type 2). In general, incidence of compressive optic neuropathy is approximately 4/100,000 cases per year [3, 10, 22-26]. Endoscopic optic nerve decompression should be performed when there is a decrease in visual acuity after an injury or compression and the optic nerve is still intact [3]. This surgery allows to avoid further damage to the nerve which is caused by edema. Moreover, it enables removal of potential bone fragments that may compromise the nerve [27]. Surgery should not be performed if the optic nerve is completely avulsed (because the nerve will not recover), the shape of the bulb has changed distinctly, anatomical difficulties do not permit surgery or if the patient is not amenable for surgery in general. The transnasal endoscopic approach for optic nerve decompression, performed by otorhinolaryngologists, is considered as gold standard providing many benefits including reduced mortality, faster recovery of patients and the minimally invasive approach (which results in a better cosmetic outcome). With the endoscopic approach, the medial, inferior and superior parts of the optic nerve canal can be reached through the lateral wall of the sphenoid sinus. If the lateral part is mainly affected, a craniotomy approach, carried out by a neurosurgeon, may be indicated $[2,3$, 28].

During surgery an incision of the optic nerve sheath can be performed for additional decompression. The benefit of this procedure is still not clear. Optic nerve sheath incision can reduce the risk for a compartmental syndrome after an injury but also carries risks such as cerebrospinal fluid leakage [3, 9, 29-31].

Regarding the optimal timing of surgery, there are different opinions on this subject matter. Yang et al. [32] achieved in 96 patients suffering from traumatic optic neuropathy the best results within a time frame of more than 3 days between injury and surgery. Tandon et al. [5] recommend 1-2 weeks as an interval. In an interventional study with 133 patients, Levin et al. [33] could not find a benefit from treating an optic nerve lesion immediately after injury. In their prospective case study of 20 patients, Gupta et al. [34] observed the best results within a time frame of $72 \mathrm{~h}$ to perform surgery. Dhaliwal et al. [12] summed up the controversial findings in a systematic review of 24 articles regarding the timing of intervention. According to them, no specific point of time is favored, but even late interventions may help to improve vision.

At our otorhinolaryngology department, the endoscopic optic nerve decompression as treatment modality for optic nerve injury has been performed since approximately two decades; however, there are no existing guidelines on surgical treatment of optic nerve injuries. This might be due to the paucity of clinical studies regarding this treatment option. Hence, the precise therapeutic benefit of surgical optic nerve decompression remains unknown. More- 
Fig. 1 Study flow diagram

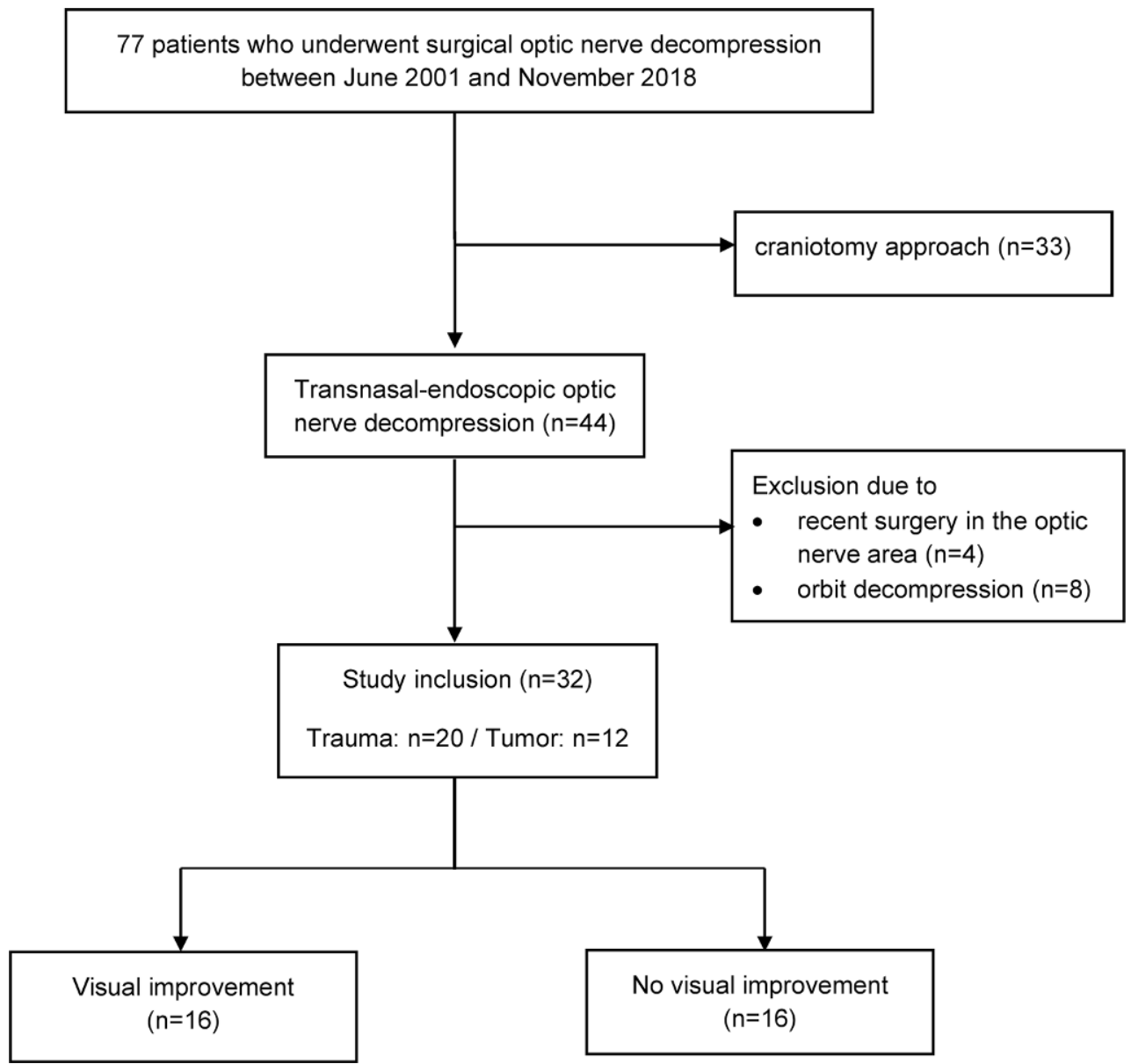

over, there is no consensus on optimal timing of surgery and the beneficial effect of additional optic nerve sheath incision as well as perioperative corticosteroid use [12, 13].

Taking these facts into account, we retrospectively evaluated in the present study all patients, who underwent endoscopic optic nerve decompression at our department, and analyzed clinical parameters, which may have had an impact on visual outcome in order to adapt the treatment management for future cases and to help establish guidelines for this treatment modality.

\section{Material and methods}

\section{Study design}

In this retrospective cohort study, data from patients at a tertiary referral center, who underwent a surgical optic nerve decompression between June 2001 and November 2018, were collected. Patients with recent surgery at the optic nerve area, a decompression of the orbit, and craniotomized patients were excluded. Collected data were statistically analyzed to compare clinical parameters that may have favored visual improvement after surgery. Therefore, patients were divided into groups according to visual improve- ment after surgical optic nerve decompression (yes vs. no). Visual improvement was determined by patient's subjective self-reports. Further subgroup analyses were conducted based on etiology (trauma vs. tumor). Assessed relevant parameters were: use of steroids (yes/no), radiological evidence of an affected optic nerve (yes/no), nerve sheath incision (yes/no), elevated C-reactive protein (CRP) levels before surgery $(\mathrm{CRP}<1 \mathrm{mg} / \mathrm{l}, 1<\mathrm{x}<10 \mathrm{mg} / \mathrm{l},>10 \mathrm{mg} / \mathrm{l})$ and time frame between injury/visual deterioration and surgery ( $<1$ day/1-3 days/>3 days/>1 week).

\section{Statistical analysis}

SPSS (C) statistical software, version 25.0 (IBM (C), Armonk, NY, USA) was used for statistical analysis. Statistical significance level was set at $p<0.05$, two-sided. Continuous variables are presented as means \pm standard deviations in case of normal distribution and as median together with range in absence of normal distribution. Normal distribution was assessed by Kolmogorov-Smirnov test. Categorical variables are expressed as absolute numbers and percentages. For comparison of categorical variables, $\chi^{2}$-test was utilized. In cases of expected cell frequencies less than 5 , the exact test method was used. The 
Table 1 Patient's demographic data

\begin{tabular}{|c|c|c|c|c|c|c|c|c|}
\hline & Total cohort & Vision impr & ment & & No vision ir & jvement & & $p$-value \\
\hline & $n=32$ & $\begin{array}{l}\text { Total }^{*} \\
n=16\end{array}$ & $\begin{array}{l}\text { Trauma** } \\
n=9\end{array}$ & $\begin{array}{l}\text { Tumorok* } \\
n=7\end{array}$ & $\begin{array}{l}\text { Total }^{*} \\
n=16\end{array}$ & $\begin{array}{l}\text { Trauma }^{\star \star} \\
n=11\end{array}$ & $\begin{array}{l}\text { Tumor } \\
n=5\end{array}$ & \\
\hline Age, years & $\begin{array}{l}45.3 \\
\text { (SD 19.3) }\end{array}$ & $\begin{array}{l}41.7 \\
\text { (SD 16.5) }\end{array}$ & $\begin{array}{l}36.2 \\
\text { (SD 17.4) }\end{array}$ & $\begin{array}{l}48.8 \\
\text { (SD 13.4) }\end{array}$ & $\begin{array}{l}48.9 \\
\text { (SD 21.6) }\end{array}$ & $\begin{array}{l}47.1 \\
\text { (SD 21.1) }\end{array}$ & $\begin{array}{l}52.8 \\
\text { (SD 24.9) }\end{array}$ & $\begin{array}{l}{ }^{*} \mathrm{t}(30)=1.1, p=0.301 \\
{ }^{*} \mathrm{t}(18)=1.2, p=0.229 \\
{ }^{* * *} \mathrm{t}(10)=0.3, p=0.729\end{array}$ \\
\hline Sex, $n$ (\%) & & & & & & & & $\begin{array}{l}{ }^{*} \chi^{2}(1)=0.5, p=0.465 \\
{ }^{\star} \chi^{2}(1)=0.1, p=0.769 \\
{ }^{\star \star \star} \chi^{2}(1)=0.3, p=0.558\end{array}$ \\
\hline Female & $\begin{array}{l}20 \\
(62.5)\end{array}$ & $\begin{array}{l}7 \\
(43.8)\end{array}$ & $\begin{array}{l}3 \\
(33.3)\end{array}$ & $\begin{array}{l}4 \\
(57.1)\end{array}$ & $\begin{array}{l}5 \\
(31.3)\end{array}$ & $\begin{array}{l}3 \\
(27.3)\end{array}$ & $\begin{array}{l}2 \\
(40)\end{array}$ & - \\
\hline Male & $\begin{array}{l}12 \\
(37.5)\end{array}$ & $\begin{array}{l}9 \\
(56.3)\end{array}$ & $\begin{array}{l}6 \\
(66.7)\end{array}$ & $\begin{array}{l}3 \\
(42.9)\end{array}$ & $\begin{array}{l}11 \\
(68.2)\end{array}$ & $\begin{array}{l}8 \\
(72.7)\end{array}$ & $\begin{array}{l}3 \\
(60)\end{array}$ & - \\
\hline
\end{tabular}

Table 2 Impact of optic nerve sheath incision during surgery on visual improvement

\begin{tabular}{lllll} 
& $\begin{array}{l}\text { Total } \\
(n=31)\end{array}$ & $\begin{array}{l}\text { Vision } \\
\text { improvement } \\
(n=15)\end{array}$ & $\begin{array}{l}\text { No vision im- } \\
\text { provement } \\
(n=16)\end{array}$ \\
\hline $\begin{array}{l}\text { Nerve sheath } \\
\text { incision, } n(\%)\end{array}$ & 15 & 6 & 9 \\
\hline $\begin{array}{l}\text { No nerve sheath incision, } \\
n(\%)\end{array}$ & 16 & $(48.4)$ & $(40)$ & $(60)$ \\
\hline$\chi^{2}(1)=0.82, p=0.366$ & & & 7 \\
\hline
\end{tabular}

effect size of statistically significance differences in Chi-squared tests was expressed by $\varphi$-coefficient.

\section{Ethical considerations}

This study was independently reviewed and approved by the institutional local ethics committee (approval number: $30-216$ ex 17/18) and was performed in accordance with the ethical guidelines of the Declaration of Helsinki. Due to the retrospective nature of this study, patient's informed consent was not obtained because clinical records were anonymized prior to analysis.

\section{Results}

Between June 2001 and November 2018, 77 patients underwent surgical optic nerve decompression at our academic center. In 33 cases, a craniotomy was used as surgical approach. These patients were treated at the institution's Department of Neurosurgery and, therefore, precise data were not available for additional analysis and direct outcome comparison. Further 12 patients were excluded: reasons for exclusion are displayed in the study flow diagram (Fig. 1). At the total end, we analyzed 32 eligible patients who were treated with endoscopic optic nerve decompression at our institution's Department of Otorhinolaryngology.

Our cohort included 12 females (37.5\%) and 20 males $(62.5 \%)$ with an average age of 45.3 years (SD: 19.3 years). Patient's demographic data are summarized in Table 1. Visual improvement was achieved in
16 patients (50\%). Optic nerve affection was caused by traumatic injury in 20 cases $(62.5 \%)$ and by a tumor in 12 cases $(37.5 \%)$. There was no significant association between etiology and visual improvement outcome (visual improvement/trauma: $n=9 / 20$ (45\%), visual improvement/tumor: $n=7 / 12(58.3 \%) ; \chi^{2}(1)=0.533$, $p=0.465)$. Traffic accidents or accidents at work (e.g. construction sites) are reported in the medical records as main traumatic injury cause. Regarding the tumor entities, the most frequent were fibrous dysplasia and meningioma with an incidence of $25 \%(n=3)$ each.

During optic nerve decompression, a nerve sheath incision was performed in 15 patients (48.4\%). In one case, surgical report was not sufficiently documented. The remaining 16 patients $(51.6 \%)$ did not have an incision. There was no statistically significant difference in nerve sheath incision rate between visual improvement groups $\left(\chi^{2}(1)=0.82, p=0.366\right)$. Detailed results are displayed in Table 2. All of the optic nerve sheath incisions were performed in traumatic injury cases $(n=15 / 20,75 \%)$.

The time frame between injury/vision deterioration and surgery ranged between less than 1 day and more than 6 months. To test a statistical relationship, time frame was divided into four categories: $<1$ day $(n=8), 1-3$ days $(n=3),>3$ days $(n=7),>1$ week $(n=14)$. There were no statistically significant differences in prevalence of time categories between visual improvement groups, neither in the total cohort analysis $\left(\chi^{2}(3)=2.12, p=0.614\right)$, nor in the trauma subgroup $\left(\chi^{2}(3)=2.94, p=0.580\right)$ and tumor subgroup $\left(\chi^{2}(3)=0.89, p=0.827\right)$. Detailed results are depicted in Table 3.

CRP levels were measured in 23 patients before surgery. The counts ranged between $0.1 \mathrm{mg} / \mathrm{l}$ and $143.9 \mathrm{mg} / \mathrm{l}$ with a median of $1.1 \mathrm{mg} / \mathrm{l}$. CRP levels were divided into three categories: 10 patients $(43.5 \%)$ had a value of $<1 \mathrm{mg} / \mathrm{l}, 7$ patients $(30.4 \%)$ of $1-10 \mathrm{mg} / \mathrm{l}$ and 6 patients $(26.1 \%)$ of $>10 \mathrm{mg} / \mathrm{l}$. No statistically significant differences were found in CRP categories between visual improvement groups, neither for the total cohort $\left(\chi^{2}(1)=1.64, p=0.500\right)$, nor for etiology 
Table 3 Impact of time frame between injury/vision deterioration and surgery on visual improvement

\begin{tabular}{|c|c|c|c|c|c|c|c|}
\hline & \multirow{2}{*}{$\begin{array}{l}\text { Total cohort } \\
n=32\end{array}$} & \multicolumn{3}{|c|}{ Vision improvement } & \multicolumn{3}{|c|}{ No vision improvement } \\
\hline & & $\begin{array}{l}\text { Total }^{*} \\
n=16\end{array}$ & $\begin{array}{l}\text { Trauma }^{\star \star} \\
n=9\end{array}$ & $\begin{array}{l}\text { Tumorork* } \\
n=7\end{array}$ & $\begin{array}{l}\text { Total }^{*} \\
n=16\end{array}$ & $\begin{array}{l}\text { Trauma }^{\star \star} \\
n=11\end{array}$ & $\begin{array}{l}\text { Tumor }_{n=5}^{\star \star \star} \\
n=5\end{array}$ \\
\hline$<1$ day & $\begin{array}{l}8 \\
(25)\end{array}$ & $\begin{array}{l}3 \\
(37.5)\end{array}$ & $\begin{array}{l}2 \\
(22.2)\end{array}$ & $\begin{array}{l}1 \\
(14.3)\end{array}$ & $\begin{array}{l}5 \\
(62.5)\end{array}$ & $\begin{array}{l}4 \\
(36.4)\end{array}$ & $\begin{array}{l}1 \\
(20)\end{array}$ \\
\hline $1-3$ days & $\begin{array}{l}3 \\
(9.4)\end{array}$ & $\begin{array}{l}1 \\
(33.3)\end{array}$ & $\begin{array}{l}0 \\
(0)\end{array}$ & $\begin{array}{l}1 \\
(14.3)\end{array}$ & $\begin{array}{l}2 \\
(66.7)\end{array}$ & $\begin{array}{l}2 \\
(18.2)\end{array}$ & $\begin{array}{l}0 \\
(0)\end{array}$ \\
\hline$>3$ days & $\begin{array}{l}7 \\
(21.9)\end{array}$ & $\begin{array}{l}3 \\
(42.9)\end{array}$ & $\begin{array}{l}2 \\
(22.2)\end{array}$ & $\begin{array}{l}2 \\
(28.6)\end{array}$ & $\begin{array}{l}4 \\
(57.1)\end{array}$ & $\begin{array}{l}1 \\
(9.1)\end{array}$ & $\begin{array}{l}2 \\
(40)\end{array}$ \\
\hline$>1$ week & $\begin{array}{l}14 \\
(43.8)\end{array}$ & $\begin{array}{l}9 \\
(64.3)\end{array}$ & $\begin{array}{l}5 \\
(55.6)\end{array}$ & $\begin{array}{l}3 \\
(42.9)\end{array}$ & $\begin{array}{l}5 \\
(35.7)\end{array}$ & $\begin{array}{l}4 \\
(36.4)\end{array}$ & $\begin{array}{l}2 \\
(40)\end{array}$ \\
\hline
\end{tabular}

Table 4 Impact of pre-op CRP levels on visual improvement

\begin{tabular}{|c|c|c|c|c|c|c|c|}
\hline & \multirow{2}{*}{$\begin{array}{l}\text { Total cohort } \\
n=23\end{array}$} & \multicolumn{3}{|c|}{ Vision improvement } & \multicolumn{3}{|c|}{ No vision improvement } \\
\hline & & $\begin{array}{l}\text { Total }^{*} \\
n=12\end{array}$ & $\begin{array}{l}\text { Trauma** } \\
n=5\end{array}$ & $\begin{array}{l}\text { Tumor*** } \\
n=7\end{array}$ & $\begin{array}{l}\text { Total }^{*} \\
n=11\end{array}$ & $\begin{array}{l}\text { Trauma** } \\
n=6\end{array}$ & $\begin{array}{l}\text { Tumor }^{\star \star *} \\
n=5\end{array}$ \\
\hline$<1 \mathrm{mg} / \mathrm{l} \mathrm{CRP}$ & $\begin{array}{l}10 \\
(43.5)\end{array}$ & $\begin{array}{l}4 \\
(33.3)\end{array}$ & $\begin{array}{l}2 \\
(40)\end{array}$ & $\begin{array}{l}2 \\
(28.6)\end{array}$ & $\begin{array}{l}6 \\
(54.5)\end{array}$ & $\begin{array}{l}3 \\
(50)\end{array}$ & $\begin{array}{l}3 \\
(60)\end{array}$ \\
\hline 1-10 mg/l CRP & $\begin{array}{l}7 \\
(30.4)\end{array}$ & $\begin{array}{l}5 \\
(41.7)\end{array}$ & $\begin{array}{l}1 \\
(20)\end{array}$ & $\begin{array}{l}4 \\
(57.1)\end{array}$ & $\begin{array}{l}2 \\
(18.2)\end{array}$ & $\begin{array}{l}1 \\
(16.7)\end{array}$ & $\begin{array}{l}1 \\
(20)\end{array}$ \\
\hline$>10 \mathrm{mg} / \mathrm{l} \mathrm{CRP}$ & $\begin{array}{l}6 \\
26.1\end{array}$ & $\begin{array}{l}3 \\
(25)\end{array}$ & $\begin{array}{l}2 \\
(40)\end{array}$ & $\begin{array}{l}1 \\
(14.3)\end{array}$ & $\begin{array}{l}3 \\
(27.3)\end{array}$ & $\begin{array}{l}2 \\
(33.3)\end{array}$ & $\begin{array}{l}1 \\
(20)\end{array}$ \\
\hline \multicolumn{8}{|c|}{$\begin{array}{l}\text { Categorical variables are presented as absolute numbers and percentages (\%) } \\
{ }^{\star} \chi^{2}(2)=1.6, p=0.500 \\
{ }^{\star \star} \chi^{2}(2)=1.1, p=0.946 \\
{ }^{\star \star \star} \chi^{2}(2)=1.7, p=0.747\end{array}$} \\
\hline
\end{tabular}

Table 5 Impact of pre-operative steroids on vision improvement

\begin{tabular}{|c|c|c|c|c|c|c|c|}
\hline & \multirow{2}{*}{$\begin{array}{l}\text { Total cohort } \\
n=32\end{array}$} & \multicolumn{3}{|c|}{ Vision improvement } & \multicolumn{3}{|c|}{ No vision improvement } \\
\hline & & $\begin{array}{l}\text { Total }^{*} \\
n=16\end{array}$ & $\begin{array}{l}\text { Trauma** } \\
n=9\end{array}$ & $\begin{array}{l}\text { Tumor }^{\star \star \star} \\
n=7\end{array}$ & $\begin{array}{l}\text { Total }^{*} \\
n=16\end{array}$ & $\begin{array}{l}\text { Trauma** } \\
n=11\end{array}$ & $\begin{array}{l}\text { Tumor } \\
n=5\end{array}$ \\
\hline Preoperative steroids & $\begin{array}{l}9 \\
(28.1)\end{array}$ & $\begin{array}{l}2 \\
(12.5)\end{array}$ & $\begin{array}{l}1 \\
(11.1)\end{array}$ & $\begin{array}{l}1 \\
(14.3)\end{array}$ & $\begin{array}{l}7 \\
(43.8)\end{array}$ & $\begin{array}{l}5 \\
(45.5)\end{array}$ & $\begin{array}{l}2 \\
(40)\end{array}$ \\
\hline No preoperative steroids & $\begin{array}{l}23 \\
(71.9)\end{array}$ & $\begin{array}{l}14 \\
(87.5)\end{array}$ & $\begin{array}{l}8 \\
(88.9)\end{array}$ & $\begin{array}{l}6 \\
(85.7)\end{array}$ & $\begin{array}{l}9 \\
(56.2)\end{array}$ & $\begin{array}{l}6 \\
(54.5)\end{array}$ & $\begin{array}{l}3 \\
(60)\end{array}$ \\
\hline
\end{tabular}

subgroups $(p>0.05)$. Detailed results are shown in Table 4.

Perioperative steroids were administered highlydosed ( $250 \mathrm{mg}$ prednisolone) by the intravenous route. In 9 of 32 cases $(28.1 \%)$, steroids were given before surgery. There were no statistically significant differences in preoperative steroid usage between visual improvement groups, neither in the total cohort analysis $\left(\chi^{2}(1)=3.8, p=0.113\right)$, nor in the trauma subgroup $\left(\chi^{2}(1)=2.8, p=0.157\right)$ and tumor subgroup $\left(\chi^{2}(1)=1.1\right.$, $p=0.523)$. Detailed results are displayed in Table 5. In 16 cases $(50 \%)$, patients received steroids before and after surgery. There was no case in which a patient received solely postoperative steroids. Administration prevalence of steroids (preoperative or preop- erativeop + postoperative) differed statistically significant between visual improvement groups $\left(\chi^{2}(1)=4.5\right.$, $p=0.033, \varphi=0.378)$. Patients without any steroid treatment had a $37.5 \%$ significantly higher prevalence of visual improvement in comparison to patients who received steroids. Concerning etiology subgroup analysis (trauma vs tumor), there were no statistically significant differences in steroid usage between visual improvement groups $(p>0.05)$. Exact details are presented in Table 6 .

From 32 patients, 18 (56.2\%) showed an affected optic nerve (compression, edema/hematoma, tumor contact, thickening, fracture of the optic channel/ foramen, gas accumulation around the nerve) in preoperative radiological imaging. There was a statisti- 
Table 6 Impact of steroid use (preoperative or preoperative + postoperative) on visual improvement

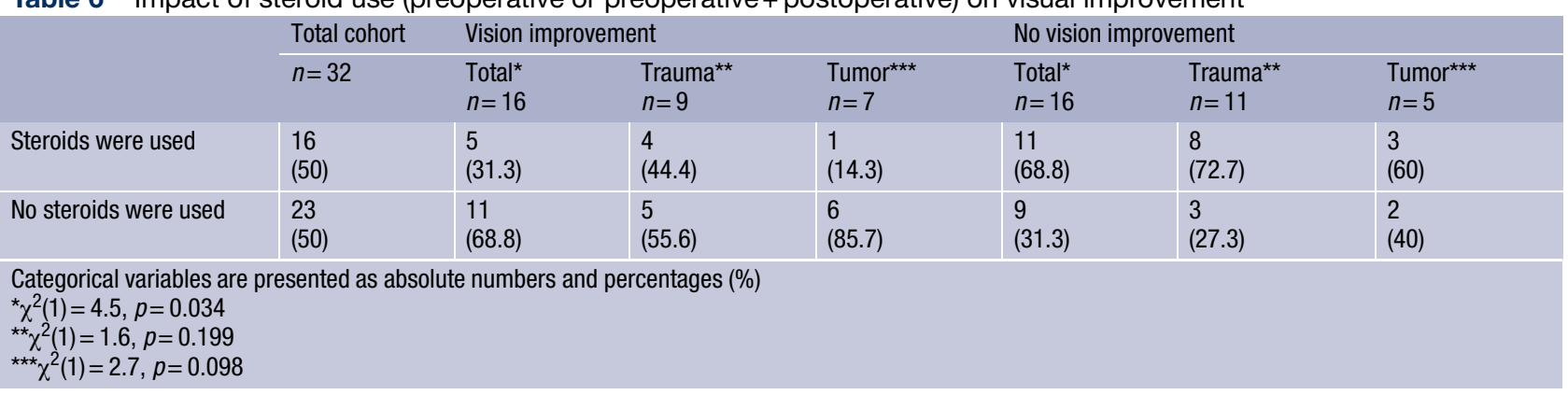

Table 7 Impact of radiological evidence of optic nerve affection on visual improvement

\begin{tabular}{|c|c|c|c|c|c|c|c|}
\hline & \multirow{2}{*}{$\begin{array}{l}\text { Total cohort } \\
n=32\end{array}$} & \multicolumn{3}{|c|}{ Vision improvement } & \multicolumn{3}{|c|}{ No vision improvement } \\
\hline & & $\begin{array}{l}\text { Total }^{\star} \\
n=16\end{array}$ & $\begin{array}{l}\text { Trauma** } \\
n=9\end{array}$ & $\begin{array}{l}\text { Tumor } \\
n=7\end{array}$ & $\begin{array}{l}\text { Total }^{*} \\
n=16\end{array}$ & $\begin{array}{l}\text { Trauma }^{\star *} \\
n=11\end{array}$ & $\begin{array}{l}\text { Tumor }{ }^{\star \star \star *} \\
n=5\end{array}$ \\
\hline Radiological evidence & $\begin{array}{l}18 \\
(56.3)\end{array}$ & $\begin{array}{l}12 \\
(75)\end{array}$ & $\begin{array}{l}5 \\
(55.6)\end{array}$ & $\begin{array}{l}7 \\
(100)\end{array}$ & $\begin{array}{l}6 \\
(37.5)\end{array}$ & $\begin{array}{l}4 \\
(36.4)\end{array}$ & $\begin{array}{l}2 \\
(40)\end{array}$ \\
\hline No radiological evidence & $\begin{array}{l}14 \\
(43.7)\end{array}$ & $\begin{array}{l}4 \\
(25)\end{array}$ & $\begin{array}{l}4 \\
(44.4)\end{array}$ & 0 & $\begin{array}{l}10 \\
(56.3)\end{array}$ & $\begin{array}{l}7 \\
(63.6)\end{array}$ & $\begin{array}{l}3 \\
(60)\end{array}$ \\
\hline
\end{tabular}

cally significant difference in radiological nerve affection prevalence between visual improvement groups in the total cohort $\left(\chi^{2}(1)=4.57 p=0.033, \varphi=0.378\right)$. According to further conducted etiology subgroup analyses, a significant difference in preoperative radiologic evidence of optic nerve affection between visual improvement groups was solely found in the tumor subgroup $\left(\chi^{2}(1)=5.6, p=0.018, \varphi=0.683\right)$, not in the trauma subgroup $\left(\chi^{2}(1)=0.7, p=0.391\right)$. Remaining details are depicted in Table 7 .

\section{Discussion}

In the present study we retrospectively evaluated 32 patients with acute optic neuropathy who were treated with transnasal endoscopic optic nerve decompression between June 2001 and November 2018 at our academic center. We could identify two clinical parameters which were significantly associated with the visual outcome after the surgical procedure: the radiological evidence of an affected/injured optic nerve in preoperative neuroimaging and the perioperative usage of corticosteroids.

Out of the 32 included patients, $50 \%(n=16)$ reported a visual improvement following endoscopic optic nerve decompression. The optic neuropathy was caused by traumatic injury in 20 cases $(62.5 \%)$ and by a tumor compression in 12 cases $(37.5 \%)$. We found no significant association between etiology and visual improvement outcome: Trauma patients showed a visual improvement rate of $45 \% \quad(n=9 / 20)$ while a visual improvement occurred in 58\% $(n=7 / 12)$ of the tumor patients.
In the total cohort, 18 patients had radiological evidence of an affected/injured optic nerve in the preoperative imaging. Out of these, 12 patients improved in vision after surgery. We observed a significantly better visual outcome if radiological evidence of damage to the optic nerve was present: according to our statistical analysis, there was a $38 \%$ significantly higher rate of visual improvement when the optic nerve was affected/injured in preoperative imaging $(p=0.033$, $\varphi=0.378$ ); however, it is important to further separate traumatic and nontraumatic cases in this context, due to their underlying etiology and received imaging modality. All patients in our cohort initially underwent CT imaging. CT is often the preferred primary imaging modality as it is fast, cost-effective, not limited by potential foreign bodies, can identify lesions nearby the optic nerve and inside the orbit, and it excellently detects bony fractures and bony fragments comprising the optic nerve [6-8]. Moreover, CT is advantageous for the preoperative evaluation of the individual sinonasal anatomy, when planning a transnasal endoscopic optic nerve decompression. In our cohort, 20 patients had a traumatic optic neuropathy with an improvement in visual function after surgery in 9 cases. These cases with visual improvement showed in $56 \%$ an optic nerve affection in the preoperative CT imaging, while those patients without visual improvement had an optic nerve injury in preoperative imaging in $44 \%$. Our results correlate with findings from previous studies: Gupta et al. [34] evaluated 20 patients with traumatic optic neuropathy and optic nerve affection in the CT neuroimaging, who were treated with endoscopic optic nerve decompression. The authors reported a visual improvement 
of $55 \%(n=11 / 20)$. Han [35] recommends in his case reports to perform an early intervention, if any bone fragments or fractures are close to the optic nerve. In contrast, Levin et al. [33] mentioned in their study that optic canal fractures and resulting damages of the optic nerve might decrease the chance of recovery. Also, they could not observe that radiological evidence in a CT scan was in a relationship with visual outcome (under consideration that they did not have a higher quantity of CT findings). Clearly, CT is the optimal imaging modality in acute optic neuropathies with a traumatic etiology; however, in nontraumatic cases, MRI is definitely the preferable neuroimaging modality, as it provides precise anatomic details for the optic nerve tissue itself [37]. In the present study, 12 patients had a nontraumatic, tumorous etiology and 7 of these cases (58\%) improved in visual function after the endoscopic optic nerve decompression. All nontraumatic cases received an additional MRI before the surgical treatment. We observed a significant difference in optic nerve affection prevalence in preoperative neuroimaging between tumor visual improvement groups $(p=0.018, \varphi=0.683)$. Out of the 9 tumor patients with optic nerve affection in preoperative neuroimaging, 7 subjects $(77 \%)$ showed a visual improvement after the surgical procedure. In other words, each of the tumor patients with visual improvement ( $n=7 / 7,100 \%)$ showed evidence of optic nerve affection in the preoperative MRI. These results indicate an association between optic nerve affection in preoperative neuroimaging and visual outcome. Certainly, CT imaging is obligatory in traumatic optic neuropathy events. In nontraumatic cases where MRI is the preferred modality, the imaging result could be helpful for decision making of endoscopic optic nerve decompression. The presence of an affected optic nerve in the MRI may be used as indication for the surgical treatment as the vast majority of surgically treated cases with evidence of nerve affection in preoperative imaging showed a visual improvement.

Corticosteroids are known to improve or avoid edema, swellings, vasospasm and to regain function when treating acute optic neuropathy [34, 38]. In recent literature, several studies could not show a beneficial effect in using corticosteroids for treatment of optic nerve compression. Entezari et al. [39] performed a double-masked randomized-controlled trial in 31 patients who suffered from an indirect traumatic optic neuropathy, 16 received a steroid therapy, 15 a placebo. They could not show a significant difference in visual improvement between these groups $(p=0.38)$. Yu-Wai-Man and Griffiths [15] concluded in their systematic review that steroids do not act beneficially in treatment. According to them, the possible disadvantages of those medications should be considered. In a retrospective review of Ropposch et al. [21], no beneficial effect of steroids could be found when they were given in addition to surgery. The findings of these studies are consistent with results of the present study: 16 of the 32 included patients (50\%) received some form of perioperative steroids, either solely preoperatively $(n=9 / 16)$ or preoperatively and postoperatively $(n=7 / 16)$. Our statistical analysis revealed a $37.5 \%$ significantly lower prevalence in visual improvement when steroids were administered. If the usage of steroids were causatively related with a poorer visual improvement remains certainly debatable; however, our data clearly support the opinion that steroids do not have a significant beneficial effect on visual recovery. Similar applies for the different etiologies, as we failed to find in both trauma and tumor subgroups, a benefit of steroid usage on visual outcome. Considering the lack of evidence for a beneficial effect and the potential disadvantages of corticosteroids, their usage as treatment option in traumatic and compressive optic neuropathy cases should be carefully considered.

An incision of the optic nerve sheath during the surgical treatment can be performed for an additional decompression. The precise benefit of this procedure remains unknown. Controversial results can be found in literature: Xu et al. [29] analyzed 74 patients with traumatic optic neuropathy and had a better visual outcome $(65.1 \%)$ in the group without nerve sheath incision than in the group with incision $(61.2 \%),(p>0.05)$. This study claims that nerve sheath incision is not implicitly necessary for optic nerve decompression. In the group of patients who had a residual visual acuity before surgery, they also observed a better outcome in patients without nerve sheath incision (64.2 and $74.1 \%, p>0.05)$. In contrast, Thaker et al. [9] found a beneficial effect of additional optic nerve sheath incision: in their prospective study including 57 patients with traumatic optic neuropathy treated with endoscopic optic nerve decompression, the improvement rate was higher when nerve sheath incision was performed additionally (improvement rate $46.6 \%$ with incision vs. $32.8 \%$ without, $p=0.10$ ). In the present study, we failed to find a beneficial effect of optic nerve sheath incision on the visual outcome $(p=0.366)$. Nevertheless, it is essential to additionally consider the underlying cause of the optic nerve injury. Therefore, we further intended to analyze the influence of optic nerve sheath incision on the visual outcome for the different etiologies. We observed that each optic nerve sheath fenestration was performed in traumatic cases, presumably in order to decrease a trauma-induced edema. Nevertheless, there was no significant association between optic nerve sheath incision and visual improvement $(p=0.719)$. Our data indicate that additional optic nerve sheath incision does not improve postoperative visual function in traumatic optic neuropathy events. These findings are concordant with those of $\mathrm{Xu}$ et al. [29]. In addition to the lack of benefit of optic nerve sheath fenestration, its potential adverse events including vessel injury, CSF leak and further iatrogenic nerve damage, must be considered [36]. 
Unfortunately, no optic nerve sheath fenestration was performed in the tumor subgroup, hence, no conclusion can be made at this point for this kind of patients. Therefore, it remains uncertain if optic nerve sheath incision has a positive effect on the visual outcome in tumor patients, and especially in which tumor entities. For instance, patients with meningioma involving the dural optic sheath may probably benefit more from an optic nerve sheath fenestration than patients with an osseous disorder like fibrous dysplasia. However, this lack of knowledge must be addressed in a future trial.

Regarding the optimal timing of surgical treatment, there are many different opinions in literature. Several studies suggested performing surgery within 3 days to get the most benefit. By keeping to this time frame, fewer long-term damages of the nerve are reported [12, 32, 34]. Tandon et al. [5] recommended to undergo surgery between 1 and 2 weeks. In contrast, Emanuelli et al. [40] showed a significant difference for beginning of surgical treatment within $12 \mathrm{~h}$ after the injury. An animal-based experimental study reported damages and changes on the molecular base of the nerve within $72 \mathrm{~h}$ after an injury [41]. In their systematic data review, Dhaliwal et al. analyzed more than 24 articles and concluded that more than $50 \%$ of the patients benefitted from surgery regardless of timing [12]. Considering these varying recommended time frames to initiate surgical treatment, we decided to divide our patients according to their time delay from symptom onset to surgery into four categories: surgery within 1 day (3 out of 8 improved, 37\%), between 1 and 3 days (1 out of 3 improved, 33\%), between 3 days and 1 week (3 out of 7 improved, $42 \%$ ) and more than 1 week (7 out of 12 improved, $64 \%$ ). There was no significant difference in surgery delay between visual improvement groups ( $p=0.614)$; however, it is necessary to additionally taken the underlying etiology into account. Therefore, we performed further subgroup analyses based on the underlying cause. Nevertheless, we also found no significant association between surgery delay and visual improvement in both trauma and tumor subgroups. These results are in concordance with the conclusion stated in the review article by Dhaliwal et al. [12]. It appears that the timing of endoscopic optic nerve decompression does not have a substantial impact on the visual outcome after the surgical procedure.

As an inflammatory blood marker, we decided to evaluate the potential influence of preoperative CRP levels on the visual outcome after endoscopic optic nerve decompression. We failed to find a significant association between preoperative CRP levels and visual outcome. Hence, higher CRP levels before surgery seem not to have negative effects on the visual outcome.

The shortcomings of our study are a small sample size, the retrospective onset and the lack of objective evaluation for visual function.

\section{Conclusion}

Considering the success rate of vision recovery (50\%) after endoscopic decompression surgery, the establishment of standard guidelines for optic nerve compressions would be an important target to improve the outcome of future patients. Regarding our results, nerve sheath incision did not result in improvement. The timing of surgery as well as elevated CRP levels did not significantly influence vision recovery. We suggest that radiological findings as indicator for surgery could help to avoid nonbeneficial surgeries. Patients with an affected nerve in preoperative imaging seem to benefit the most from a surgical intervention. In the case of an undamaged nerve, a wait-and-see strategy may be considered. The use of steroids should be reevaluated and investigated with prospective studies analyzing their value in current therapy.

Funding No funding was received for conducting this study.

Author Contribution All authors made substantial contributions to the conception or design of the work or the acquisition, analysis, or interpretation of data and drafted the work and revised it critically for important intellectual content and approved the version to be published and agree to be accountable for all aspects of the work in ensuring that questions related to the accuracy or integrity of any part of the work are appropriately investigated and resolved.

Funding Open access funding provided by Medical University of Graz.

\section{Declarations}

Conflict of interest I. Leitner, A. Andrianakis, V. Gellner, P. Kiss, D. Andrianakis and P.V. Tomazic declare that they have no competing interests.

Ethical standards This study was independently reviewed and approved by the institutional local ethics committee (approval number: $30-216$ ex 17/18) and was performed in accordance with the ethical guidelines of the Declaration of Helsinki. Due to the retrospective nature of this study, patient's informed consent was not obtained because clinical records were anonymized prior to analysis.

Open Access This article is licensed under a Creative Commons Attribution 4.0 International License, which permits use, sharing, adaptation, distribution and reproduction in any medium or format, as long as you give appropriate credit to the original author(s) and the source, provide a link to the Creative Commons licence, and indicate if changes were made. The images or other third party material in this article are included in the article's Creative Commons licence, unless indicated otherwise in a credit line to the material. If material is not included in the article's Creative Commons licence and your intended use is not permitted by statutory regulation or exceeds the permitted use, you will need to obtain permission directly from the copyright holder. To view a copy of this licence, visit http://creativecommons.org/licenses/by/4.0/. 


\section{References}

1. Behbehani R. Clinical approach to optic neuropathies. Clin Ophthalmol. 2007;1:233-46.

2. Reiß M. Facharztwissen HNO-Heilkunde. Heidelberg: Springer; 2009.

3. Luxenberger W, Stammberger H, Jebeles JA, Walch C. Endoscopic optic nerve decompression: the Graz experience. Laryngoscope. 1998;108:873-82.

4. Grehn F. Augenheilkunde. 31st ed. Berlin, Heidelberg: Springer; 2012 .

5. TandonV,MahapatraA.Currentmanagementofopticnerve injury. Indian J Neurosurg. 2017;06:83-5.

6. Kumaran AM, Sundar G, Chye LT. Traumatic optic neuropathy: a review. Craniomaxillofac Trauma Reconstr 2015;08:31-41.

7. Kubal W. Imaging of orbital trauma. Radiographics. 2008;28:1729-39.

8. Peng A, Li Y, Hu P, Wang Q. Endoscopic optic nerve decompression for traumatic optic neuropathy in children. Int J Pediatr Otorhinolaryngol. 2011;75:992-8. https://doi.org/ 10.1016/j.ijporl.2011.05.004.

9. Thaker A, Tandon DA, Mahapatra AK. Surgery for optic nerve injury: Should nerve sheath incision supplement osseous decompression? Skull Base. 2009;19:263-71.

10. Parker RT, Ovens CA, Fraser CL, Samarawickrama C. Optic nerve sheath meningiomas: prevalence, impact, and management strategies. Eye Brain. 2018;10:85-99.

11. Karimi S, Arabi A, Ansari I, Shahraki T, Safi S. A systematic literature review on traumatic optic neuropathy. JOphthalmol. 2021; https://doi.org/10.1155/2021/5553885.

12. Dhaliwal SS, Sowerby LJ, Rotenberg BW. Timing of endoscopic surgical decompression in traumatic optic neuropathy: a systematic review of the literature. Int Forum Allergy Rhinol. 2016;6:661-7.

13. Berhouma M, Jacquesson T, Abouaf L, Vighetto A, Jouanneau E. Endoscopic endonasal optic nerve and orbital apex decompression for nontraumatic optic neuropathy: surgical nuances and review of the literature. Neurosurg Focus. 2014;37:1-9.

14. Yu-Wai-Man P. Traumatic optic neuropathy - clinical features and management issues. Taiwan J Ophthalmol. 2015;5:3-8.

15. Yu-Wai-Man P, Griffiths PG. Steroids for traumatic optic neuropathy. Cochrane Database Syst Rev. 2013;6:CD6032.

16. Steinsapir KD, Goldberg RA, Sinha S, Hovda DA. Methylprednisolone exacerbates axonal loss following optic nerve trauma in rats. Restor Neurol Neurosci. 2000;17:157-63.

17. Sauerland S, Nagelschmidt M, Mallmann P, Edmund AM. Risks and benefits of preoperative high dose methylprednisolone in a systematic review. Drug Saf. 2000;23:449-61.

18. Lew H, Lee S, Jang JW, Kim HY, Kang SJ, Kim SJ. The effects of high-dose corticosteroid therapy on optic nerve head blood flow in experimental traumatic optic neuropathy. Ophthalmic Res. 1999;31:463-9.

19. Lima V, Burt B, Leibovitch I, Prabhakaran V, Goldberg RA, Selva D. Orbital compartment syndrome: the ophthalmic surgical emergency. Surv Ophthalmol. 2009;54:441-9. https://doi.org/10.1016/j.survophthal.2009.04.005.

20. Steinsapir KD. Treatment of traumatic optic neuropathy with high-dose corticosteroid. J Neuroophthalmol. 2006;26:65-7.

21. Ropposch T, Steger B, Meço C, Emesz M, Reitsamer H, Rasp G, et al. The effect of steroids in combination with optic nerve decompression surgery in traumatic optic neuropathy. Laryngoscope. 2013;123:1082-6.
22. Rodriguez-Beato FY, De Jesus O. Compressive optic neuropathy. 2021. https://www.ncbi.nlm.nih.gov/books/ NBK560583/?report=classic, StatPearls. Accessed: November 12,2021 .

23. DeKlotz TR, Stefko ST, Fernandez-Miranda JC, Gardner PA, Snyderman CH, Wang EW. Endoscopic endonasal optic nerve decompression for fibrous dysplasia. J Neurol Surg B Skull Base. 2017;78:24-9.

24. Lazarus JH. Epidemiology of Graves' orbitopathy (GO) and relationship with thyroid disease. Best Pract Res Clin Endocrinol Metab. 2012;26:273-9. https://doi.org/10. 1016/j.beem.2011.10.005.

25. Huang K, Kranz PG, Green J, Adamson DC. Pituitary adenoma part I: epidemiology and clinical presentation. Contemp Neurosurg. 2011;33:1-3.

26. Hirata K, Ito Y, Tsuruta W, Takigawa T, Marushima A, Sato M, et al. Treatment outcomes of cerebral aneurysms presenting with optic neuropathy: a retrospective case series. Asian J Neurosurg. 2019;14:499-505.

27. Kong DS, Shin HJ, Kim HY, Chung SK, Nam DH, Lee JI, et al. Endoscopic optic canal decompression for compressive optic neuropathy. JClin Neurosci. 2011;18:1541-5. https:// doi.org/10.1016/j.jocn.2011.02.042.

28. PletcherSD, Metson R. Endoscopic optic nerve decompression for nontraumatic optic neuropathy. Arch Otolaryngol Head NeckSurg. 2007;133:780-3.

29. Xu R, Chen F, Zuo K, Ye X, Yang Q, Shi J, et al. Endoscopic optic nerve decompression for patients with traumatic optic neuropathy: Is nerve sheath incision necessary? ORLJ Otorhinolaryngol RelatSpec. 2014;76:44-9.

30. Patel A. Functional endoscopic sinus surgery (FESS). 2016. https://emedicine.medscape.com/article/863420-print. Accessed: November 12, 2021.

31. Pletcher S, Sindwani R, Metson R. Endoscopic orbital and optic nerve decompression. Otolaryngol Clin North Am. 2006;39:943-58.

32. Yang QT, Zhang GH, LiuX, Ye J, Li Y. The therapeutic efficacy of endoscopic optic nerve decompression and its effects on the prognoses of 96 cases of traumatic optic neuropathy. J Trauma Acute Care Surg. 2012;72:1350-5.

33. Levin LA, Beck RW, Joseph MP, Seiff S, Kraker R. The treatment of traumatic optic neuropathy: the International Optic Nerve Trauma Study. Ophthalmology. 1999;106:1268-77.

34. Gupta D, Gadodia M. Transnasal endoscopic optic nerve decompression in post traumatic optic neuropathy. Indian JOtolaryngol Head Neck Surg. 2018;70:49-52.

35. Han SR. Why doweneed optic nerve decompression of traumatic optic neuropathy patients? Interdiscip Neurosurg. 2014;1:66-7. https://doi.org/10.1016/j.inat.2014.07.006.

36. Maza G, Subramaniam S, Yanez-Siller J, Otto B, PrevedelloD, Carrau R. The role of endonasal endoscopic optic nerve decompression as the initial management of primary optic nerve sheath meningiomas. J Neurol Surg B Skull Base. 2019;80:568-76.

37. Attia M, Kandasamy J, Lee DLY, Anand VK. The importance and timing of optic canal exploration and decompression during endoscopic endonasal resection of tuberculum sella and planum sphenoidale meningiomas. Neurosurgery. 2012;71:58-67.

38. Chen F, Zuo K, Feng S, Guo J, Fan Y, Shi J, et al. A modified surgical procedure for endoscopic optic nerve decompression for the treatment of traumatic optic neuropathy. NAm JMed Sci. 2014;6(6):270-3.

39. Entezari M, Rajavi Z, Sedighi N, Daftarian N, Sanagoo M. High-dose intravenous methylprednisolone in recent traumatic optic neuropathy; a randomized double-masked 
placebo-controlled clinical trial. Graefes Arch Clin Exp Ophthalmol. 2007;245(9):1267-71.

40. Emanuelli E, Bignami M, Digilio E, Fusetti S, Volo T, Castelnuovo P. Post-traumatic optic neuropathy: our surgical and medical protocol. Eur Arch Otorhinolaryngol. 2015;272:3301-9.
41. Mabuchi F, Aihara M, Mackey MR, Lindsey JD, Weinreb RN. Optic nerve damage in experimental mouse ocular hypertension. Invest Ophthalmol Vis Sci. 2003;44:4321-30.

Publisher's Note Springer Nature remains neutral with regard to jurisdictional claims in published maps and institutional affiliations. 